\title{
Electron Channeling Effects in EPMA Analyses of Bulk Specimen Materials
}

\author{
Frederick Meisenkothen, ${ }^{*}$ Robert Wheeler,* Michael D. Uchic, ${ }^{* *}$ Robert D. Kerns, ${ }^{*}$ Frank J. \\ Scheltens*
}

*Air Force Research Laboratory, Materials Characterization Facility, Bldg. 655, $10^{\text {th }}$ and M St., Wright Patterson Air Force Base, OH 45433.

**Air Force Research Laboratory, Materials and Manufacturing Directorate, Bldg. 655, 2230 Tenth St. Wright Patterson Air Force Base, OH 45433.

Electron channeling effects can create measurable signal intensity variations in all product signals that result from the scattering of the electron beam within a crystalline specimen. Of particular concern to the x-ray microanalyst are any variations that occur within the characteristic x-ray signal that are not directly related to a specimen composition variation. Many studies have documented the effect of crystallographic orientation on the local x-ray yield; however, the vast majority of these studies were carried out on thin foil specimens examined in transmission. Only a few studies have addressed these effects in bulk specimen materials, and these analyses were generally carried out at common SEM microanalysis overvoltages $(>1.5)$. At these overvoltage levels, the magnitude of the observed variation in the characteristic x-ray signal is expected to be on the order of a few percent. As a result, the effect of electron channeling on the characteristic $x$-ray signal intensity has traditionally been overlooked in the field of quantitative electron probe microanalysis (EPMA). In the present study, the combined results from work with bulk specimens of GaAs, TaC, and Commercially Pure Ni indicate that the characteristic x-ray production rate will vary with crystallographic orientation and analysis overvoltage. The orientation dependent effect on the $\mathrm{x}$-ray production process becomes greater for low overvoltage analyses (as the overvoltage approaches unity) and variations of up to $26 \%$, between intensity maxima and minima, have been observed in low overvoltage $\mathrm{x}$-ray microanalyses of these bulk specimen materials. Intensity variations of this magnitude will significantly impact the accuracy of qualitative and quantitative $\mathrm{x}$-ray microanalyses at low overvoltage on engineering materials.

While the characteristic $x$-ray signal will vary with crystallographic orientation, additional work is needed to gain a better understanding of how the sign and the magnitude of the signal will vary with crystallographic orientation. No special specimen surface preparations are necessary to observe this effect, so long as the layer of residual plastically deformed material near the specimen surface is minimized. The specimen preparation procedures used here are conventional procedures that are commonly employed in laboratories for the preparation of structural materials specimens. While the present study has been concerned with common aerospace structural materials, there is no reason to expect that the results should be any different for other crystalline materials. Further, electron channeling effects on x-ray microanalysis will be encountered more frequently as low-damage surface preparation procedures and more efficient $\mathrm{x}$-ray detection systems become commonplace.

\section{References}

[1] This work was supported under AFRL contract \# F33615-03-C-5206.

[2] We are thankful for the help of the following people : Hamish Fraser, Krishnamurtha Mahalingam, the staff of the Lehigh Microscopy School, the members of the East Coast Cameca Users group, Lawrence Matson, David Mahaffey, Robert Lewis, Kevin Shiveley, Michel Outrequin, Pierre Monsallut, Alan Randall, and Jared Shank. 
A

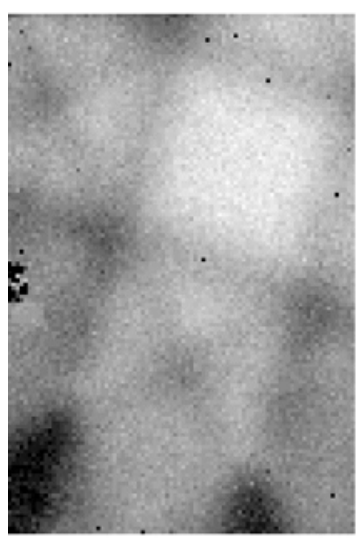

B

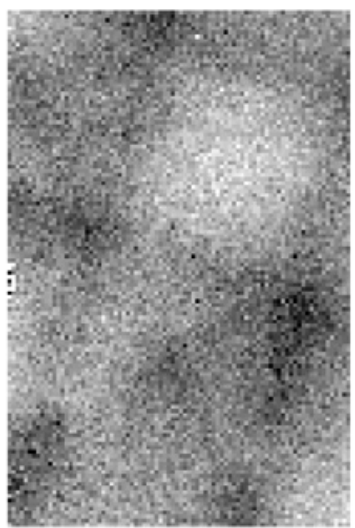

C

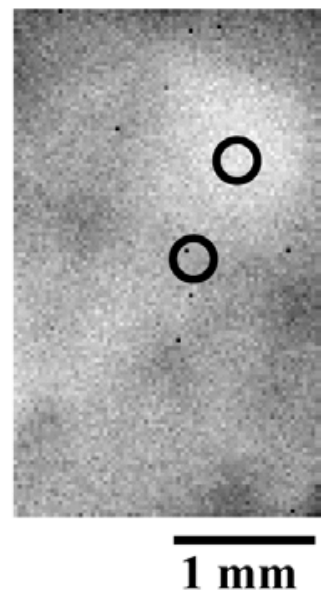

Figure 1: GaAs [100] oriented single crystal electron channeling pattern, $15 \mathrm{keV}$. A) Backscatter electron image. B) EDS x-ray image (total x-rays entering the detector). C) EDS x-ray image comprised of only the GaL $\alpha$ and AsL $\alpha$ peaks. The difference in total L $\alpha$ x-ray yield between the two circled regions indicated on the channeling pattern is about 3\% (high overvoltage approximately $=12.5, \mathrm{Eo}=15 \mathrm{keV}, \mathrm{E}_{\mathrm{c}}$ for $\mathrm{GaL} \alpha=1.12 \mathrm{keV}, \mathrm{E}_{\mathrm{c}}$ for $\mathrm{AsL} \alpha=1.32 \mathrm{keV}$, beam convergence $=3 \mathrm{mrad}$ ).

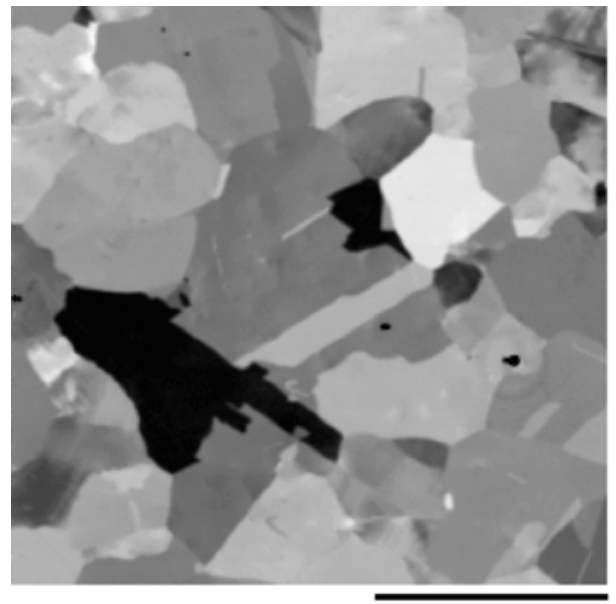

A

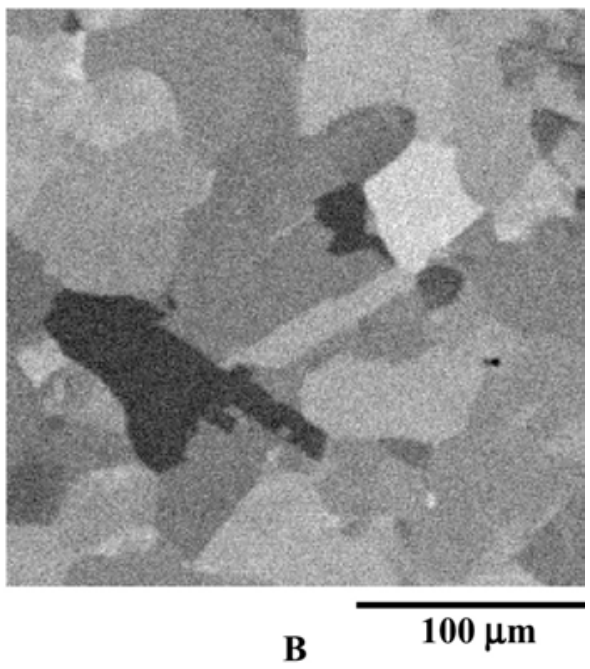

B

Figure 2: Commercially Pure Nickel, final polish colloidal silica (low overvoltage $=1.08, \mathrm{E}_{\mathrm{o}}=9 \mathrm{keV}$, $\mathrm{E}_{\mathrm{c}}$ for $\mathrm{NiK} \alpha=8.33 \mathrm{keV}$, beam convergence $=20 \mathrm{mrad}$ ). A) Backscatter electron image. B) NiK $\alpha$ WDS x-ray image. The average number of x-ray counts per pixel for the darkest grain is 1361, while the lightest grain yielded an average of 1715 counts (a 26\% greater $x$-ray yield over the darkest grain). 